\title{
Миграционная политика на Дальнем Востоке России: вызовы и перспективы
}

\begin{abstract}
Введение
Миграционные процессы на Дальнем Востоке России в минувшее десятилетие складывались под влиянием как положительных, так и отрицательных фракторов. В целях предотвращения оттока населения с Дальневосточного региона и увеличения демографического потенциала в последние годы российским правительством принят целый ряд стратегических решений, начиная с проведения в 2012 г. Саммита АТЭС в г. Владивостоке, принятия в 2015 г. Ф3 "О Территории опережающего социально-экономического развития" и утверждения проекта "Свободный порт Владивосток", в 2016 г. утверждения программы "Дальневосточный гектар".

Одновременно с этим изменилась географическая структура прибывающих в регион трудовых мигрантов при значительном увеличении доли низкоквалифицированной рабочей силы из стран Средней Азии при уменьшении доли специалистов в области сельского хозяйства, строительства, рыбной и лесной промышленности из приграничных районов КНР и КНДР.

Несмотря на эти решения, по данным, публикуемым Федеральной службой государственной статистики (Росстат), в период с 2005 г. по 2019 г. численность населения Дальневосточного Федерального округа сократилась на $4,9 \%$ из них доля трудоспособного населения от общей численности на 7,5\%, а населения старше трудоспособного возраста увеличилась на 5,4\% [17].

Последствиями этих тенденций является устойчиво нарастающий дефрицит высококвалифицированной рабочей силы, низкоквалифицированных рабочих кадров, помимо этого растет общая нагрузка на имеющуюся на Дальнем Востоке социальную инфраструктуру (учреждения здравоохранения, образования, дошкольного воспитания), а также возникновение предпосылок для межнациональных конфликтов и роста правонарушений в использовании уникальных природных ресурсов суши и моря.

Именно этой проблеме были посвящены многие сессии очередного Восточного-экономического форума, который прошел с участием президента Российской Федерации 2-4 сентября 2021 г. с обсуждением среднесрочной государственной политики совершенствования регулирования миграционных процессов на Дальнем Востоке и научном обосновании её основных положений.

Основная целевая установка исследования состоит в том, чтобы выявить и систематизировать основные проблемы ухудшения демографической ситуащии на Дальнем Востоке России. В качестве объекта исследования мы обозначаем миграционные потоки на Дальнем Востоке. Предмет исследования - организационно-методические аспекты, связанные с выявлением причин миграции на Дальнем Востоке.

Впервые за последние пять лет авторами сделана оценка миграционных потоков, с использованием комплексных данных: статистические данные, данные ведомств и министерств, результаты собственных исследований.
\end{abstract}

\section{(C) Латкин А. П., Чупахина Л. Е., 2021}

ЛАТКИН Александр Павлович, д-р экон. наук, руководитель Института подготовки кадров высшей квалификации Владивостокского государственного университета әкономики и сервиса (2. Владивосток). E-mail: aleksandr.latkinp@vvsu.ru

ЧУПАХИНА Любовь Евгеньевна, аспирант кафедры международных отношений и права, ассистент кафедры межкультурных коммуникаций и переводоведения Владивостокского государственного университета экономики и сервиса (2. Владивосток). E-mail: lyubov.chupahina04@, vvsu.ru 
Значимость настоящего исследования заключается в получении новых знаний о тенденциях и проблемах миграции на Дальнем Востоке России, в том числе в условиях пандемии.

Теоретическую и методологическую основу исследования составляют научные работы в области вопросов управления трудовой миграции, её влияние на демоградоческие и социально-экономические аспекты, в частности работы Е.В. Авдеева, в которых выявлены основные направления внутрироссийской миграции, состояния и тенденции развития миграционных процессов в России; научные работы С.Н. Мищук, которая раскрывает проблемы международной миграции и реализацию современной международной политики на Дальнем Востоке России. В процессе исследования применялись общенаучные методы (обобщение, анализ, сравнение, сощиологический опрос), статистические методы, метод систематизации.

Информационной базой исследования служат статистические материалы Росстата (https://rosstat.gov.ru/), Приморскстата (https://primstat.gks.ru/), МВД России (https://xn--b1aew.xn--p1ai/), информационные ресурсы сети Интернет, официальные сайты министерств и органов, в том числе сайт Правительства Приморского края и органов исполнительной власти Приморского края (https://www.primorsky.ru/), результаты собственных авторских опросов и исследований, в том числе проведенных и в настоящее время ещё не опубликованных.

\section{Результаты исследования}

За последние десятилетия миграционный прирост на Дальнем Востоке в значительной степени компенсировал более половины естественной убыли населения. Однако здесь наблюдается постоянный отток населения в сравнении с другими субъектами Российской Федеращии. Существенное влияние на формирование постоянного населения Дальневосточного региона России оказывала и оказывает трансграничная миграция.

Кадровый дефицит - одно из главных препятствий в реализации крупных инвестпроектов, которые сегодня разворачиваются на Дальнем Востоке. Квалифицированных специалистов приходится завозить извне. На фоне зарплат местных кадров их труд стоит гораздо дороже.

К работе в различных сферах в дальневосточном регионе привлечены мигранты из стран Средней Азии, КНР и КНДР. По последним данным Федеральной службой государственной статистики (Росстат), в период с 2011 г. по 2019 г. численность иностранных граждан, имеющих действующее разрешение на работу в Дальневосточном федеральном округе, увеличилась на $21,1 \%$ [17], что несомненно говорит о привлекательности данного региона для трудовых мигрантов. Также важно учитывать, что для развития Дальнего Востока изначально привлекались мигранты как из бывших союзных республик, так и из западных регионов страны.

Между тем за последние десятилетия прослеживается тенденция ослабления некогда сильной мотивации к работе мигрантов КНР. Наиболее серьезно пострадала строительная отрасль: вместе с экономикой Китая выросли и зарплаты китайских рабочих, так что сегодня они могут больше заработать у себя на родине, чем на дальневосточных стройках. Плюс сказывается демографическая ситуация в ДФО. Только Приморский край за три месяца 2021 г. потерял собственного населения больше 5 тысяч человек [16].

Несомненно, важную роль в притоке китайских мигрантов играет многолетнее партнерство Китая и России как на государственном уровне, так и на региональных уровнях, реализуя совместные крупные проекты, такие как "Освоение Быстринского месторождения в Забайкальском крае" и "Создание Российско-Китайского агрохолдинга на Дальнем Востоке с АО "Легендагро Холдинг". Также сотрудничество двух стран активно развивается в сельском хозяйстве, науке и технике. Помимо этого, важнейшая роль отводится совместным мерам по противодействию негативным последствиям пандемии, снижению финансовых, экономических и социальных рисков и поиску новых способов борьбы с распространением коронавируса.

Однако, согласно ведомственной статистической отчетности МВД России, в 2017 г. в Россию на работу прибыло 140 тыс. граждан КНР, в 2018 г. 123 тыс., а в 2020 г. 33,5 тыс. человек, то есть за четыре года приток сократил- 
ся на $24 \%$ [8]. Конечно, стоит учитывать фракт распространения новой коронавирусной инфекции и закрытия границ, тем не менее представленные данные говорят о постепенном снижении притока трудовых мигрантов из КНР и осуществлением ими лишь временной трудовой деятельности на территории Российской Федерации.

Вместе с тем в большинстве регионов Дальнего Востока преобладают преимущественно квалифицированные и высококвалифицированные специалисты из КНР. Граждане Китая заняты в добыче полезных ископаемых, лесной и сельскохозяйственной промышленности, строительстве, гостиничном бизнесе.

По мнению А. П. Латкина и С. В. Кузьминой развитие процессов международной трудовой миграции на Дальнем Востоке России и активное вовлечение мигрантов в народное хозяйство положительно скажется на экономическом развитии региона [6].

Еще с 2000-х гг. к работе в различных сферах в Дальневосточном регионе привлекались трудовые мигранты КНДР. Более 10 тыс. северных корейцев приезжали в Россию по рабочим визам преимущественно на Дальний Восток. Помимо этого, из-за замедления экономического роста и политических репрессий в КНДР большой приток беженцев пересек границу Российской Федерации в надежде найти укрытие и, пусть и нелегальную, но работу.

Северокорейские мигранты занимали различные должности на территории Дальневосточного федерального округа, в частности, арматурщики, бетонщики, каменщики, укладчики плитки, обойщики. Вторая по востребованности профрессия - швея.

Однако, 22 декабря 2017 г. Совет Безопасности ООН единогласно одобрил резолющию 2397, которая ввела новый пакет санкций в отношении КНДР. Страны - члены ООН должны немедленно приступить к высылке на родину северокорейских трудовых мигрантов не позднее, чем до 2019 г. Ужесточение санкционного режима было вызвано проведением 29 ноября 2017 г. испытания северокорейской баллистической ракеты нового типа [15]. К концу 2019 г. большинство северокорейских рабочих покинули Россию, оставшиеся на территории страны (в общей сложности около 1 тысячи человек) платы за свою работу уже не получали [13].

Если говорить о мигрантах из Средней Азии, то большинство из них занимают на рынке труда ниши, которые не заполняются местными работниками: водители автобусов и такси, уборщики, дворники, кассиры, повара. Важно отметить, что трудовая миграция и денежные переводы мигрантов на родину становятся способом выживания для их семей и обеспечивают их фринансовую независимость.

В целом миграционный коридор между Россией и Средней Азией является одним из самых устойчивых в мире со времен распада СССР. С 1990 по 1992 гг. наблюдался обильный поток вынужденной миграции в Россию из-за нестабильной политической и экономической ситуации.

На сегодня основными странами, из которых прибывают трудовые мигранты в Россию из Средней Азии, являются Узбекистан, Таджикистан и Кыргызстан. По данным Министерства внутренних дел Российской Федерации, в 2018 г. из Узбекистана прибыло около 2 млн. мигрантов, уже к 2019 г. их количество выросло на 100 тыс. Из Таджикистана за аналогичный период прибыл 1 млн. мигрантов, в 2018 г. их число увеличилось пости на 200 тыс. Из Кыргызстана в 2018 г. приехали в Россию около 400 тыс. мигрантов, а через год уже на 250 тыс. больше [8].

В 2020 г. началась пандемия новой коронавирусной инфекции по всему миру. В связи с этим многие трудовые мигранты покинули территорию Российской Федерации и вернулись на родину. По последним данным МВД РФ в 2020 г. на работу в Россию прибыло около 1 млн. мигрантов из Узбекистана, более 500 тыс. из Таджикистана, из Кыргызстана приблизительно 200 тыс. Конечно, не вся трудовая миграция носит легальный характер, поэтому указать точное число трудовых мигрантов сложно.

Многие трудовые мигранты рассматривают Россию и, в частности, Дальний Восток не только как место для трудоустройства, но и как территорию для постоянного проживания. Они и их дети уже несколько лет держат положительное сальдо, то есть из региона уезжает меньше мигрантов, чем ежегодно 
Рис. 1. Динамика международной трудовой миграции в ДФО

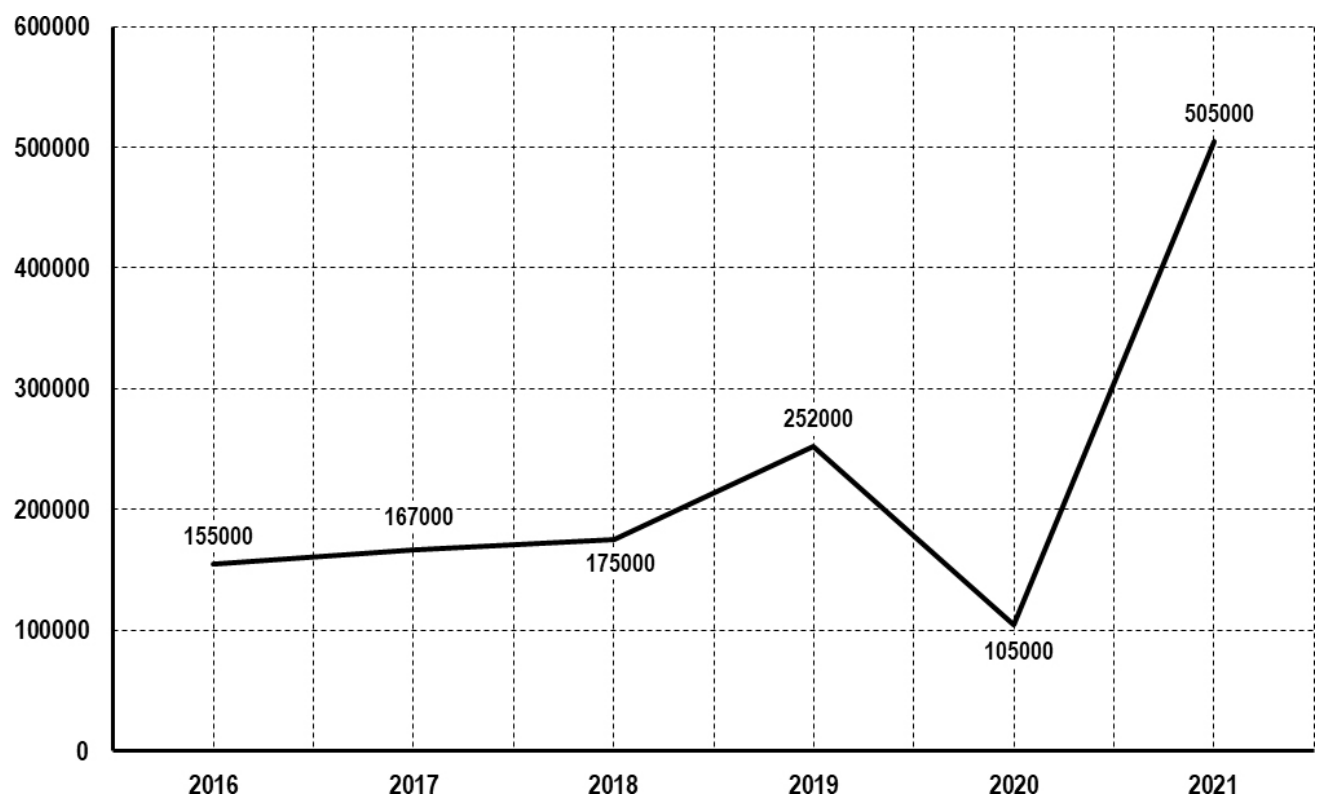

Источник: [14].

въезжает. Однако, стоит учитывать и влияние пандемии на потоки миграции в стране, регионе и мире в целом. В 2020 г. в дальневосточном регионе отмечено отрицательное сальдо, то есть иностранных мигрантов выехало больше, чем въехало, что, несомненно, присуще и другим регионам Российской Федерации. Такое резкое падение обусловлено ничем иным, как поспешным закрытием границ в связи со стремительным распространением новой коронавирусной инфекции и ухудшением эпидемиологической обстановки по всему миру.

Однако, по данным МВД России, в период с января по сентябрь 2021 г. в Дальневосточный федеральный округ уже прибыло около 505 тыс. трудовых мигрантов, что почти на 21\% больше по сравнению со статистикой 2020 г. (puc. 1) [14].

Отмечается ужесточение требований к привлечению трудовых мигрантов виде запретов или ограничений.

В настоящее время причины запрета на трудовых мигрантов касаются не только экологических, но и социально-экономических аспектов (всё чаще говорится о необходимости борьбы с теневым сектором в әкономике в целом и в сельском хозяйстве в частности; о необходимости повышения налоговых платежей в бюджет региона и использовании труда местных жителей) [7].

Для проведения грамотной политики сдерживания миграционных потоков правительством Российской Федерации был принят целый ряд мер, таких как экзамен, позволяющий определить уровень сформированности у иностранного гражданина коммуникативно-речевой компетенции по русскому языку, истории России и основам законодательства РФ. Помимо этого, с 29 декабря 2021 г. для всех трудовых мигрантов станет обязательной дактилоскопия в России.

31 октября 2018 г. Указом Президента Российской Федерации № 622 была утверждена Концепция государственной миграционной политики Российской Федерации на 2019-2025 гг. Данная концепция предполагает создание миграционной ситуации, которая способствует решению задач в сфрере социально-экономического и демографического развития страны, совершенствование системы регулирования привлечения иностранной рабочей силы, повышения качества жизни ее населения, обеспечения безопасности государ- 
Табл 1. Динамика оттока населения по регионам Дальнего Востока (в тыс.чел.)

\begin{tabular}{|l|c|c|c|c|c|c|}
\hline & $\mathbf{2 0 1 5}$ & $\mathbf{2 0 1 6}$ & $\mathbf{2 0 1 7}$ & \multicolumn{1}{c|}{$\mathbf{2 0 1 8}$} & \multicolumn{1}{c|}{$\mathbf{2 0 1 9}$} & \multicolumn{1}{c|}{$\mathbf{2 0 2 0}$} \\
\hline Дальневосточный федеральный округ & $\mathbf{2 1 3 2 6 0}$ & $\mathbf{2 1 5} \mathbf{8 0 7}$ & $\mathbf{2 2 1} \mathbf{5 2 4}$ & $\mathbf{3 6 1 6 0 9}$ & $\mathbf{3 4 1} 647$ & $\mathbf{2 4 6} 823$ \\
\hline Республика Бурятия & - & - & - & 45751 & 44350 & 37776 \\
\hline Республика Саха (Якутия) & 35430 & 35339 & 39519 & 45278 & 42634 & 33178 \\
\hline Забайкальский край & - & - & - & 36683 & 34572 & 24385 \\
\hline Камчатский край & 9661 & 9136 & 8823 & 15539 & 15760 & 9898 \\
\hline Приморский край & 65322 & 64919 & 66095 & 82567 & 79762 & 57464 \\
\hline Хабаровский край & 44638 & 45589 & 44628 & 58143 & 54035 & 33064 \\
\hline Амурская область & 26132 & 26270 & 26601 & 32788 & 29592 & 23064 \\
\hline Магаданская область & 4678 & 6394 & 6807 & 9746 & 8662 & 5552 \\
\hline Сахалинская область & 18741 & 19462 & 20748 & 24651 & 21498 & 14931 \\
\hline Еврейская автономная область & 4423 & 4499 & 4022 & 5299 & 5307 & 3428 \\
\hline Чукотский автономный округ & 4235 & 4199 & 4281 & 5164 & 5475 & 4083 \\
\hline
\end{tabular}

Источник: составлено на основе [12].

ства, защиты национального рынка труда, поддержания межнационального и межрегионального мира и согласия в российском обществе.

Однако, несмотря на то, что поток желающих получить российское гражданство и приехать на работу в Россию не иссякает, убыль коренного населения дальневосточников не прекращается (табл. 1).

С февраля по апрель 2021 г. авторами в рамках выявленной проблемы были проведены социологические опросы в ряде школ Приморского края среди выпускников старших классов, а также среди студентов третьего курса высшего учебного заведения. Исследование показало, что среди 126 опрошенных около $10 \%$ не планируют поступать в вузы Дальнего Востока или продолжать в них обучение по программам магистратуры и далее аспирантуры, а, наоборот, видят перспективу дальнейшего обучения в центральных вузах России. Исходя из результатов, проведенных авторами оценочного опроса, был сделан вывод, что для Дальневосточного региона формировалась и формируется неблагоприятная тенденция изменения возрастной структуры покидающих регионы Дальнего Востока при значительном увеличении доли молодежи: успешные выпускники средних общеобразовательных школ и высших учебных заведений.

Однако, стоит отметить, что Правительство Российской Федерации старается принимать противоборствующие меры, понимая, что регион "теряет" перспективную часть своего населения. Так полномочный представитель президента на Дальнем Востоке Юрий Трутнев во время пресс-конференции в Чите выступил с предложением выплачивать по 1 млн. рублей выпускникам, окончившим учебное заведение с золотой медалью. Основным условием выплаты этих средств будет учеба в вузе и дальнейшее трудоустройство на территории Дальневосточного региона. Эта мера будет направлена на сокращение оттока молодежи с Дальнего Востока России. Кроме того, в начале сентября 2021 г. стало известно, что Ростуризм собирается запустить на Дальнем Востоке программу молодёжного обмена по аналогии с американской Work and Travel. Она позволит молодёжи временно поработать в регионе. Запустить программу планируют уже в 2022 г. Насколько эта мера будет эфрфективна, на сегодняшний день сказать трудно, однако правительство ежегодно утверждает проекты, направленные на решение демоградической проблемы на Дальнем Востоке, но их результативность пока не подтверждается на практике. 
Помимо этого, можно выделить ещё ряд причин оттока молодежи с Дальневосточного региона России, одной из которых является дорогостоящее жильё. В 2019 г. была запущена программа "Дальневосточная ипотека", которая подразумевает выдачу кредитов под $2 \%$ годовых на покупку жилья в Дальневосточном фредеральном округе. В рамках этой программы молодые семьи смогут построить или улучшить своё жильё. Главной целью является сокращение убыли населения и, по мнению правительства, такая программа будет способствовать развитию строительного рынка в Дальневосточном регионе вплоть до 2025 г. Однако существуют определенные риски и условия. Заёмщиками могут стать лишь граждане РФ до 35, состоящие в браке минимум год, также граждане, не состоящие в браке, но воспитывающие ребенка до 18 лет. Взяв ипотеку под $2 \%$, дальневосточники обязаны отчитаться о месте регистрации, а процентная ставка при определенных условиях может возрасти.

Согласно "Концепции государственной миграционной политики Российской Федеращии на период до 2025 года" по итогам реализации второго этапа предполагается к 2021 г. приостановить миграционный отток населения из районов Сибири и Дальнего Востока.

Между тем молодые люди продолжают покидать Дальний Восток, невзирая на привлекательные ипотечные условия и субсидированные перевозки. Даже программа "Дальневосточный гектар", реализация которой регламентируется положениями Федерального закона от 1 мая 2016 г. № 119-Ф3 "Об особенностях предоставления гражданам земельных участков, находящихся в государственной или муниципальной собственности и расположенных на территориях субъектов Российской Федерации, входящих в состав Дальневосточного федерального округа, и о в несении изменений в отдельные законодательные акты Российской Федерации" [18] не дала желаемых результатов, и уровень трудоспособного населения в регионе ежегодно снижается.

По оценкам экспертов, чтобы переломить ситуацию, необходимо строить систему адресного опережающего обучения специалистов под потребности отраслей и ключевые инвестпроекты. Эти планы реализуются общими усилиями региональных властей, крупных работодателей и руководства вузов.

Так, дальневосточные колледжи присоединились к международной образовательной программе "Управление изменениями в системе профрессиональной подготовки для экономики регионов" от инновационного центра "Сколково". Инициатива нацелена на создание новых, эфрфективных подходов к обучению студентов колледжей и развитие таких приоритетных отраслей, как "Судостроение", "Энергетика", "Лесное хозяйство", "Сельское хозяйство", "Строительство" и "Туристско-рекреационное направление". Например, в Приморье программа должна способствовать увеличению внутреннего турпотока в 2,7 раза, росту поступлений в краевой бюджет в 1,6 раза, увеличению численности работников, занятых в сфере туризма и гостеприимства, на 23 тысячи человек, росту в 1,5 раза оборота гостиниц и других организаций, предлагающих туристские услуги.

Конечная целью правительства страны - остановить отток населения с Дальнего Востока. Отметим, что Правительство Российской Федерации в июне 2017 г. приняло Концепцию демографического развития Дальнего Востока до 2025 г. В ней определили, что на Дальнем Востоке к 2025 г. должно жить 8,7 млн. человек.

\section{Заключение}

Дальний Восток России - это эпицентр действия для инвесторов, желающих вложить деньги в значимые проекты. Именно в Приморском крае начался Свободный порт Владивосток, и здесь открыта одна из первых Территорий опережающего социально-экономического развития.

Однако многие предприятия сталкиваются с нехваткой рабочей силы в области судостроения, сельскохозяйственной, лесной и пищевой промышленности, в добыче угля и авиапромышленности. Растет спрос и на квалифицированных рабочих и инженеров.

Количество мигрантов, прибывающих на Дальний Восток в поисках работы, не компенсирует естественную убыль населения из региона. Конечно, Дальний Восток - окраина России, и меры миграционной политики, которые 
принимает правительство, привлекая мигрантов из разных стран и регионов, не работают в полной мере.

Очевидно, что трудовая миграция в регионе помогает решать его социально-экономические и демографические проблемы, однако на фроне амбициозных проектов развития Дальнего Востока механизмы для эффективного привлечения квалифицированных специалистов, а также для предотвращения оттока трудоспособного населения из региона до конца не отработаны, о чем свидетельствуют последние данные.

\section{Литература}

1. Авдеев Е.В. Основные направления внутрироссийской миграции / Е.В. Авдеев, К.С. Терновых // Московский экономический журнал 2019. № 6. С. 350-358.

2. Авдеев Е.В. Миграционные отношения России с зарубежными странами: структура международной миграции [Электронный ресурc]. URL: https://qje.su/ ekonomicheskaya-teoriya/moskovskij-ekonomicheskij-zhurnal-8-2019-93/?print=print (дата обращения: 15.10.2021).

3. Воробьева О.Д. Рынок труда и миграция населения Дальнего Востока // Уровень жизни населения регионов России. 2017. № 2. С. 35-40. [Электронный ресурс]. URL: https://cyberleninka.ru/article/v/rynok-truda-i-migratsiya-naseleniya-dalnegovostoka (дата обращения: 15.10.2021).

4. Дудин М.Н. Современные аспекты социально-демографической ситуации в дальневосточных регионах России // Региональная экономика: теория и практика. 2016. Т. 14. Вып. 11. С. $160-169$.

5. Киреев А.А. Пограничная политика России на Дальнем Востоке: динамика задач и результатов // Проблемы Дальнего Востока. 2017. № 3. С. 95-108.

6. Латкин А.П., Кузьмина С.В. Трудовая миграция из КНР в российское Приморье: основные предпосылки и новые подходы к регулированию // Управление экономическими системами: электронный научный журнал. 2014. № 12. С. 61.

7. Мищук С.Н. Реализация современной миграционной политики на Дальнем Востоке России: федеральный и региональный аспекты. 2018, т. 16, вып. 6, стр. 10281040.

8. Министерство внутренних дел Российской Федерации. Отдельные показатели миграционной ситуации в Российской Федерации. https://xn--b1aew.xn--p1ai/ Deljatelnost/statistics (дата обращения: 15.10.2021).

9. Мищук С.Н. Международная трудовая миграция в регионе: проблемы трансграничного взаимодействия // Региональная экономика. 2010. Т. 8. № 36. С. 3743. [Электронный pecypc]. URL: https://cyberleninka.ru/article/v/mezhdunarodnayatrudovaya-migratsiya-v-regioneproblemy-transgranichnogo-vzaimodeystviya (дата обращения: 15.10 .2021$)$.

10. Официальный сайт правительства Приморского края и органов исполнительной власти Приморского края [Электронный pecypc]. URL: https://www.primorsky.ru/ (дата обращения: 15.10.2021) (дата обращения: 15.10.2021).

11. Романов И.А. Особенности государственного регулирования миграции на Дальнем Востоке // Социологические исследования. 2004. № 11. С. 52-56.

12. Росстат: Официальная статистика. Население. Демографоя. Миграция. [Электронный pecypc]. URL: https://rosstat.gov.ru/folder/12781 (дата обращения: 15.10.2021).

13. Русская служба BBC news [Электронный ресурc]. URL: https://www.bbc.com/ russian/features- 42989901

14. Статистические сведения по миграционной ситуации МВД РФ. [Электронный pecypc]. URL: https://xn--b1aew.xn--p1ai/dejatelnost/statistics/migracionnaya (дата обращения: 15.10 .2021 ).

15. ТАСС. Информационное агентство. Санкции ООН в отношении КНДР. ТАСС. https://tass.ru/info/4837818 (дата обращения: 15.10.2021).

16. Территориальный орган Федеральной службы государственной статистики по Приморскому краю [Электронный ресурc]. URL: https://primstat.gks.ru/ (дата обращения: 15.10 .2021$)$.

17. Федеральная служба государственной статистики. Регионы России. Социально-экономические показатели 2020. Стат. сб. / Росстат. М., 2020. / [Электронный реcypc]. URL: https://rosstat.gov.ru/folder/12781 (дата обращения: 15.10.2021).

18. Федеральный Закон "Об особенностях предоставления гражданам земельных участков, находящихся в государственной или муниципальной собственности и расположенных на территориях субъектов Российской Федерации, входящих в состав Дальневосточного федерального округа, и о внесении изменений в отдельные законодательные акты Российской Федеращии" от 01.05.2016 г. № 119-Ф3 / [Электронный pecypc]. URL: http://www.consultant.ru/document/cons_doc_LAW_197427/. (дата обращения: 15.10 .2021$)$. 


\section{Транслитерация по ГОСТ 7.79-2000 Система Б}

1. Avdeev E.V. Osnovnye napravleniya vnutrirossijskoj migratsii / E.V. Avdeev, K.S. Ternovykh // Moskovskij ehkonomicheskij zhurnal 2019. № 6. S. 350-358.

2. Avdeev E.V. Migratsionnye otnosheniya Rossii s zarubezhnymi stranami: struktura mezhdunarodnoj migratsii [EHlektronnyj resurs]. URL: https://qje.su/ekonomicheskaya-teoriya/moskovskij-ekonomicheskij-zhurnal-8-2019-93/?print=print (data obrashheniya: 15.10 .2021 ).

3. Vorob'eva O.D. Rynok truda i migratsiya naseleniya Dal'nego Vostoka // Uroven' zhizni naseleniya regionov Rossii. 2017. № 2. S. 35-40. [EHlektronnyj resurs]. URL: https://cyberleninka.ru/article/v/rynok-truda-i-migratsiya-naseleniya-dalnego-vostoka (data obrashheniya: 15.10.2021).

4. Dudin M.N. Sovremennye aspekty sotsial'no-demograficheskoj situatsii v dal'nevostochnykh regionakh Rossii // Regional'naya ehkonomika: teoriya i praktika. 2016. T. 14. Vyp. 11. S. $160-169$.

5. Kireev A.A. Pogranichnaya politika Rossii na Dal'nem Vostoke: dinamika zadach i rezul'tatov // Problemy Dal'nego Vostoka. 2017. № 3. S. 95-108.

6. Latkin A.P., Kuz'mina S.V. Trudovaya migratsiya iz KNR v rossijskoe Primor'e: osnovnye predposylki i novye podkhody k regulirovaniyu // Upravlenie ehkonomicheskimi sistemami: ehlektronnyj nauchnyj zhurnal. 2014. № 12. S. 61.

7. Mishhuk S.N. Realizatsiya sovremennoj migratsionnoj politiki na Dal'nem Vostoke Rossii: federal'nyj i regional'nyj aspekty. 2018, t. 16, vyp. 6, str. 1028-1040.

8. Ministerstvo vnutrennikh del Rossijskoj Federatsii. Otdel'nye pokazateli migratsionnoj situatsii v Rossijskoj Federatsii. https://xn--b1aew.xn--p1ai/Deljatelnost/statistics (data obrashheniya: 15.10.2021).

9. Mishhuk S.N. Mezhdunarodnaya trudovaya migratsiya $\mathrm{v}$ regione: problemy transgranichnogo vzaimodejstviya // Regional'naya ehkonomika. 2010. T. 8. № 36. S. 3743. [EHlektronnyj resurs]. URL: https://cyberleninka.ru/article/v/mezhdunarodnaya-trudovaya-migratsiya-v-regioneproblemy-transgranichnogo-vzaimodeystviya (data obrashheniya: 15.10 .2021$)$

10. Ofitsial'nyj sajt pravitel'stva Primorskogo kraya i organov ispolnitel'noj vlasti Primorskogo kraya [EHlektronnyj resurs]. URL: https://www.primorsky.ru/ (data obrashheniya: 15.10.2021) (data obrashheniya: 15.10.2021).

11. Romanov I.A. Osobennosti gosudarstvennogo regulirovaniya migratsii na Dal'nem Vostoke // Sotsiologicheskie issledovaniya. 2004. № 11. S. 52-56.

12. Rosstat: Ofitsial'naya statistika. Naselenie. Demografiya. Migratsiya. [EHlektronnyj resurs]. URL: https://rosstat.gov.ru/folder/12781 (data obrashheniya: 15.10.2021).

13. Russkaya sluzhba BBC news [EHlektronnyj resurs]. URL: https://www.bbc.com/ russian/features-42989901

14. Statisticheskie svedeniya po migratsionnoj situatsii MVD RF. [EHlektronnyj resurs]. URL: https://xn--b1aew.xn--p1ai/dejatelnost/statistics/migracionnaya (data obrashheniya: 15.10 .2021$)$.

15. TASS. Informatsionnoe agentstvo. Sanktsii OON v otnoshenii KNDR. TASS. https://tass.ru/info/4837818 (data obrashheniya: 15.10.2021).

16. Territorial'nyj organ Federal'noj sluzhby gosudarstvennoj statistiki po Primorskomu krayu [EHlektronnyj resurs]. URL: https://primstat.gks.ru/ (data obrashheniya: 15.10.2021).

17. Federal'naya sluzhba gosudarstvennoj statistiki. Regiony Rossii. Sotsial'no-ehkonomicheskie pokazateli 2020. Stat. sb. / Rosstat. M., 2020. / [EHlektronnyj resurs]. URL: https://rosstat.gov.ru/folder/12781 (data obrashheniya: 15.10.2021).

18. Federal'nyj Zakon "Ob osobennostyakh predostavleniya grazhdanam zemel'nykh uchastkov, nakhodyashhikhsya v gosudarstvennoj ili munitsipal'noj sobstvennosti i raspolozhennykh na territoriyakh sub"ektov Rossijskoj Federatsii, vkhodyashhikh v sostav Dal'nevostochnogo federal'nogo okruga, i o vnesenii izmenenij v otdel'nye zakonodatel'nye akty Rossijskoj Federatsii" ot 01.05.2016 g. № 119-FZ / [EHlektronnyj resurs]. URL: http:// www.consultant.ru/document/cons_doc_LAW_197427/.(data obrashheniya: 15.10.2021). 
Латкин А. П., Чупахина Л. Е. Миграционная политика на Дальнем Востоке России: вызовы и перспективы.

В последние десятилетия миграционные процессы имеют нарастающие масштабы как в мировой экономической системе, так и в Российской Федерации, где во многих регионах, особенно на Дальнем Востоке, существует значительный дефицит собственной квалифицированной рабочей силы. В настоящей статье приводятся результаты исследований основных причин устойчивого оттока экономически активного населения с различных дальневосточных регионов за последние десять лет. Сделан вывод о низкой обеспеченности трудовыми ресурсами созданных в последние годы предприятий в 22-х Территориях опережающего социально-экономического развития (ТОР) и Свободном порту Владивосток (СПВ), которые могут быть обеспечены за счет миграционных связей с КНР, КНДР и странами Средней Азии. Авторами выявлены тенденции в изменении географической структуры прибывающих на территорию Дальнего Востока трудовых мигрантов, определены проблемы нормативно-правового и социально-экономического регулирования миграционных потоков на государственном, региональном и местном уровнях. Сформулированы предложения по совершенствованию государственной миграционной политики в среднесрочной перспективе, в том числе с учетом негативных последствий пандемии новой коронавирусной инфекции.

Ключевые слова: миграционная политика, миграционные потоки, международная миграция, государственное регулирование, тендениии, российский Дальний Восток, оценка влияния, географбческая структура, последствия пандемии

Latkin A. P., Chupakhina L. E. Migration policy in the Russian Far East: challenges and prospects.

In recent decades, migration processes have been growing in scale both in the global economic system and in the Russian Federation, where in many regions, and especially in the Far East, there is a significant shortage of their own qualified labor force. This article presents the results of studies of the main reasons for the steady outflow of the economically active population from various Far Eastern regions over the past ten years. The conclusion is made about the low availability of labor resources for enterprises created in recent years in the Territory of Advanced Social and Economic Development and the Free Port of Vladivostok, which can be provided through migration links with the PRC, North Korea and the countries of Central Asia. The authors identified trends in the change in the geographical structure of labor migrants arriving in the Far East, identified the problems of legal and socio-economic regulation of migration flows at the state, regional and local levels. Proposals have been formulated to improve the state migration policy in the medium term, including considering the negative consequences of the new coronavirus pandemic.

Key words: migration policy, migration flows, international migration, government regulation, trends, Russian Far East, impact assessment, geographical structure, consequences of pandemic

Для цитирования: Латкин А. П., Чупахина Л. Е. Миграционная политика на Дальнем Востоке России: вызовы и перспективы // Ойкумена. Регионоведческие исследования. 2021. № 4. C. 15-23. DOI: $10.24866 / 1998-6785 / 2021-4 / 15-23$

For citation: Latkin A. P., Chupakhina L. E. Migration policy in the Russian Far East: challenges and prospects i/ Ojkumena. Regional researches. 2021. № 4. P. 15-23. DOI: $10.24866 / 1998-6785 / 2021-4 / 15-23$ 